\title{
The emotional and embodied nature of human understanding: sharing narratives of meaning
}

\author{
Jonathan Delafield-Butt \\ University of Strathclyde \\ AUTHOR'S ACCEPTED MANUSCRIPT \\ PREPRINT
}

This is a draft of a chapter that has been accepted for publication by Oxford University Press in:

The Child's Curriculum: Working with the Natural Values of Young Children. (2018). Colwyn Trevarthen, Jonathan Delafield-Butt, Aline-Wendy Dunlop (Eds.). Oxford: Oxford University Press.

ISBN: 9780198747109

available at https://global.oup.com/academic/product/the-childs-curriculum$\underline{9780198747109 ? \mathrm{cc}=\mathrm{gb} \& \text { lang }=\mathrm{en} \&}$ 


\begin{abstract}
This chapter explores the emotional and embodied nature of children's learning to discover biological principles of social awareness, affective contact, and shared sense-making before school. From mid gestation, simple self-generated actions of a foetus learn to anticipate their sensory effects. They generate a small 'story' that progresses through time, giving meaningful satisfaction on their successful completion. Self-made stories become organised after birth into complex projects requiring greater appreciation of their consequences, which are communicated. They are mediated first by brainstem conscious control made with vital feelings, which motivates a more abstract, cortically mediated cognitive and cultural intelligence in later life. By tracing development of meaning-making from simple projects of the infant to complex shared projects in early childhood, we appreciate the embodied narrative form of human understanding in healthy affective contact, how it may be disrupted in children with clinical disorders or educational difficulties, and how it responds in joyful projects to an understanding teacher's support for learning.
\end{abstract}




\section{Introduction: the narrative nature of knowledge}

On a hot and humid day in Texas in 1962 John F. Kennedy made an impassioned speech on the grounds of Rice University (Kennedy 1962). His remarks set in motion a space race that would send a man to the moon for the first time in human history. To achieve this technical mastery with rational logic, and cognitive foresight he engaged a fundamental psychological mode of intelligence that exist in human life from the beginning. He told a narrative - a story to be shared - with a grand goal that motivated participation. It was affective, it generated hopes and aspirations in each one of its listeners. And it would set in place America's technical dominance of the world for the next fifty years,

"We choose to go to the moon... [applause]. We choose to go to the moon... [applause]. We choose to go to the moon in this decade and do the other things, not because they are easy, but because they are hard, because that goal will serve to organize and measure the best of our energies and skills, because that challenge is one that we are willing to accept, one we are unwilling to postpone, and one we intend to win." (J. F. Kennedy, Rice University Speech, 12 September 1962, italics mine)

Like an inspiring teacher before his class, Kennedy created a sense of cohesion and belonging that everyone could contribute to. Its biological origin is the power of narrative to motivate, inspire, include, and give direction to individual lives and activity, within the coherence of a community. Kennedy initiated a narrative, a project with a clear collective goal that all individuals could contribute to, no matter their level of knowledge or skill. This is a fundamental source of personal belonging. Served well it can be a source of inclusion, and good health. And it is required by any community of learners in a classroom, too.

\section{Children's agency in the shared generation of meaning}

There are two psychological principles that drive human agency. One is, "I like to move it" - there is deep satisfaction in moving the body, and moving well. The second principle is, "I like to move it with you" - we are fundamentally social creatures with strong emotional ties.

Nobel Laureate Roger Sperry made the profound point that movement is our only means of expression and communication, "the sole product of brain function is motor coordination" (Sperry 1952, p.297). All our feelings, intentions, and desires, thoughts and aspirations are made evident through movement of the body. And we desire to share them with others, it is a human need. 
Shaun Gallagher, a phenomenologist or philosopher of direct experience, illustrated this feature of human nature by calling the pain of solitary confinement (Gallagher 2014). One of the harshest punishments that our penal system can impose is to confine someone alone. It is painful not to be social, and goes against our nature.

Moving one's self with another person gives life meaning. An infant moves to generate common understanding in engagement (Delafield-Butt and Trevarthen 2013; Trevarthen and Delafield-Butt 2013a). Movement of self-generated, affect-driven, and intentional acts brings pleasure, and movements made in positive concert with social others create joy, bringing our culture to life (Frank and Trevarthen 2012).

Self-driven, and affective meaning-making is first evident at the very beginning of a human life in how a foetus makes purposeful movements of limbs and careful changes of posture that may be regulated for social contact (Castiello, Becchio, Zoia, et al. 2010; Delafield-Butt and Gangopadhyay 2013). The first intentions of the baby after birth are adapted to share awareness of life intimately, at first with the mother, in consensuality with her love (Maturana-Romesin and Verden-Zoller 2008).

\section{Successful acts become repeated as schemas of thought, feeling, and action}

This willful, self-generated behaviour first evident in foetal life becomes the basis of learning how the world responds, and what it offers. Learning the echoes or reflections caused by our movements build what Jean Piaget called a 'sensorimotor intelligence', which he claimed is the foundation of later conceptual intelligence. Piaget's predecessor James Mark Baldwin (1895) had recognized these 'circular reactions', which couple self-generated movement with expected sensation, must be the foundation of intelligence that will become more conscious with growing perceptual foresight,

"the self-repeating or circular reaction is seen to be fundamental and to remain the same, as far as structure is concerned, for all motor activity whatever: the only difference between higher and lower functioning being, that in the higher, certain accumulated adaptations have in time so come to overlie the original reaction, that the conscious state which accompanies it seems to differ per se from the crude imitative consciousness in which it had its beginning."

(Baldwin 1895, p. 23)

Acts made consciously that succeed in their purpose bring satisfaction. They are learned and can be repeated to achieve that same sense of satisfaction again and again. They can be adapted to suit new occasions, a schema of intention and action that holds affective value - satisfaction in its 
success - both intrinsically and shared. Baldwin perceived that circular reactions of human intelligence, even as "the crude imitative consciousness" are specially adapted to be shared. $\mathrm{He}$ perceived that the plans of movement seeking sensory confirmation are ready for communication and the building of a cooperative life.

In the 1980s, Berry Brazelton, Dan Stern, Colwyn Trevarthen, Ed Tronick, Beatrice Beebe, Stein Bråten and others observed infants closely and proved a contingent, reciprocal nature of infant actions made with another person in dialogue, or proto-conversation. They established evidence for an innate intersubjective, or interpersonal, nature of human minds - a position in agreement with what the philosopher Martin Buber called the primary 'I-Thou' consciousness, from which develops objective 'I-It' consciousness of how we share use of things in the world (Buber Ich und $D u$ 1923, quoted in Friedman 2002, p.193). We do not need the rational mentalising of a complex neocortex to begin cooperating with each other's purposes, and acquiring habits of 'common sense'.

\section{Primary intentions are conceived in the embodiment of brainstem, not the rationality of cortex}

Contempoary cognitive neuroscience, intending to explain knowledge of facts, reasons and symbolic language, often forgets that the cerebral cortex sits on top of more ancient neural structure that is nonetheless in service of fundamental psychological function for thought and intelligence. The brainstem is anatomically sub-cortical, but in the structuring of thought, experience, and learning its functionally super-cortical, serving to organise and informer a higher order, rational intelligence (Merker 2007). In development and through a life of learning, it recruits the activity of the cortex in projects of movement-with-feeling organised through time (Damasio 2003; Goodrich 2010). The brainstem mid-brain system is now recognised as the centre of a primary self-as-agent, and of its emotions and affectivity. It guides rhythms of self-related processing that evaluate the risks and benefits in any action, and responds to the forms and emotions of movements made by other selves (Panksepp 1998).

Observations of the human fetus, with analysis of intentionality in movement recorded by fourdimension ultrasound movies, shows that this basic self-consciousness is developing at fourteen to sixteen weeks gestational age (Delafield-Butt and Gangopadhyay 2013; Reissland and Kisilevsky 2015). This is an age when the cerebral cortex is not yet functional, but there is a brainstemmediated intelligence, which, studied by Jaak Panksepp, proves to be the seat of the Core SELF (Northoff and Panksepp 2008; Panksepp and Biven 2012), and which is identified by Bjorn Merker 
as the essential neurological substrate for consciousness of inquisitive vitality in body movement (Merker 2007).

The brain-stem integrates and commands three dimensions of activity, which contribute the foundations of intentionality and the affective regulation of the person. It has a interoceptive awareness or an awareness of information picked up within the body to sense the 'visceral' functions that sustain life -- of heartbeat, blood oxygenation, energy reserves, temperature regulation and digestion of food and elimination of waste. It has a biomechanical proprioceptive sense, which is an awareness of forces of the body in motion, through the system of stretch receptors in the muscles and joints. And it also has an exteroceptive awareness of the outside world, which is typically what we think of as our sensory field of consciousness, what we 'know' by vision, smell, touch, and hearing. These senses together give the brainstem a consciousness of the vital needs of the body (interoception), as it is moving (proprioception) through the world (exteroception). This is the intuitive motivator of our person, and it does not require additional cognitive, cortical machinery to integrate purposes in a reasoned awareness of life, or 'theory of mind'. Neuroscientist Philip Winn suggests that "we need to put the brain back into brain stem" (Winn 2012), the primary site of affective and associative learning often ignored in neuroscience of intelligence.

Long ago, two pioneering neurosurgeons, Penfield and Jasper (1954), proposed the 'centrencephalic theory' of consciousness at the centre of the encephalon (head), to describe the brainstem complex. Treating brain disorders, they performed a large number of large cortical resections, or inactivated the cortex during operations, and were surprised by the consciousness these patients retained. Children born with loss of most of their cerebral cortices, due to hydranencephaly or anencephaly, may still enjoy affectionate social and emotional lives and control their own actions with conscious purpose, although they are severely cognitively debilitated (Shewmon, Holmse and Byrne 1999; Merker 2007). We do not need a cerebral cortex to be conscious, to have feelings, to act with intentions, to perceive and appraise the environment, to engage socially and purposefully with others, or to learn. Indeed experiments with rats demonstrate that, with the cortex removed, these animals are able to navigate over tricky terrain, perform courtship rituals, copulate, and wean litters (Wood 1964).

The cortex is certainly the seat of complex, adult, conceptual intelligence, the constructs of what Thomas Reid (1764) called 'artificial language', a technical language. But we want to understand Reid's other 'natural language', because this is the language of children that remains vital in our adult lives as well - colouring with feeling and emotion everything we do, and giving the embodied and emotional foundation to our advanced technical intelligence. 


\section{Child development from simple intentions to ambitious projects}

All our activities are composed of elementary units of intention (Figure 1). When we reach to grasp something, our intention is carried out in the extension of the arm in a very simple movement, which is followed by movements of the hand that take the object up, then use it. Reaching is organized with anticipation of its goal to use the object, its physical action is organized by its intention. Prospective organization of movement appears to be a biological universal (Delafield-Butt, Pepping, McCaig and Lee 2012). If the intention differs, for example to pick up a bottle of wine to pour it or to put it on a shelf, so too does all the preceding structure of the physical acts (Jeannerod 1998).

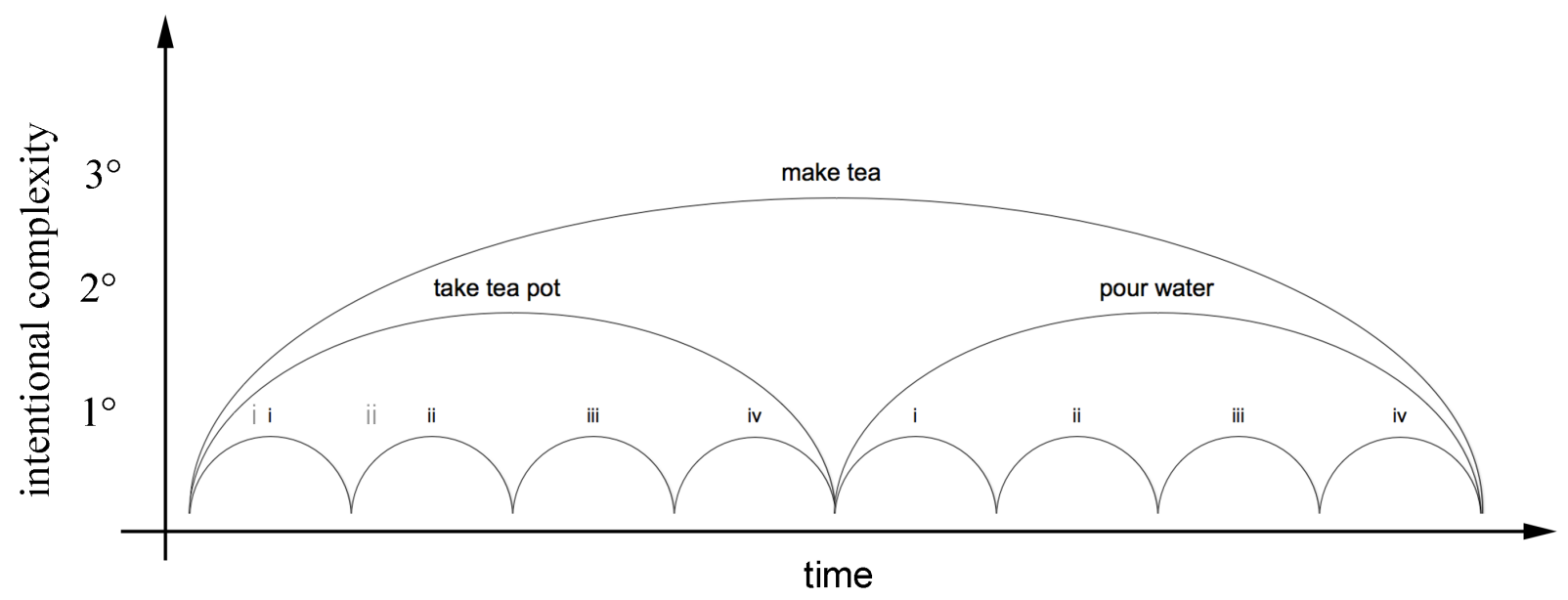

Figure 1. Levels of organization of motor intentions built on $\left(1^{\circ}\right)$ individual 'action units' toward immediate goals; $\left(2^{\circ}\right)$ proximal projects that structure and coordinate elementary actions; and $\left(3^{\circ}\right)$ projects of projects that become abstract and conceptually rich. Early skill incorporates intentions from the basic, primary level to the tertiary. For example, the idea to 'make tea' is accomplished by a sequence of secondary levels of intention; to 'take tea pot,' 'pour water,' each composed of a sequence of more proximal sensorimotor actions: (i) reach and (ii) grasp the tea pot, (iii) place into position, and (iv) release; (i) reach and (ii) grasp the kettle, and (iii) pour water into the tea pot before (iv) returning the kettle to its resting position. This kind of every-day task with imaginative variations may become a favourite 'game' in a children's nursery. Such unitary and embedded organization of practical skill enables learning of a rich repertoire of possible projects (Delafield-Butt and Trevarthen 2015). 
In the beginning, the fetus can reach with care to touch the umbilical cord, the placenta, or a twin. And it can make grasping movements. The actions an older child who is playing with a toy, after that initial reach-to-touch, add an accommodating plan to adapt the movement creatively in play, exploring and expanding the child's knowledge of things, and beginning to take many eventualities into account.

These intentional actions are organized in a hierarchy of purpose that expands from its simple beginnings. To have a cup of tea one must reach, grasp, then move the object to one's mouth, then tip the cup and coordinate one's mouth movements to drink from it. Hand and cup are used as tools, in contrast to putting one's head right down to the water to drink, as a dog or horse would do. Manual manipulation of objects requires planning learned within the child's social environment. A one-year-old can drink from a cup using his hands in the proper way, having learned, by 'sharing a task', to use that tool like a parent does (Hubley and Trevarthen 1979). Contrast this with the Wild Boy of Aveyron who grew up with wolves, rather than with his human parents, and drank water like wolves (x). Learned social intelligence within affective bonds is innate (Packard and Delafield-Butt 2014). This instrumental I-It learning is the beginning of our higher-order cultural intelligence, which needs planning of the serial organization of movement in a conventional way ahead of time. It enables us to achieve more distal goals, further away from us in space and time and in complexity of action -including rituals of art, speech, literature and manufacturing techniques that may be inherited from ancestors.

To enable this kind of special human 'ritual intelligence' (Merker 2010), the child needs to develop playfully the cognitive machinery of planning, to organize concepts and memory in imagination, to piece together an understanding of the world that came from understanding the consequences of simple actions (Pezzulo and Castelfranchi 2009). Now the mind of the toddler can extrapolate meaning further into the future, making up stories of make believe, creative imagination.

We may plan to drink tea together, performing elaborate, well organized rituals of sitting together, waiting for the appropriate moment to pour the water, stir the tea, and pour the tea into tea cups, all the while sharing a conversation with its grammatical rules and imitative, reciprocal exchange of expression to qualify semantic details. Each act or project has a particular temporal domain. The primary acts are always typically under one second, the small projects between one and three seconds, and then these larger tertiary projects are always over three seconds, because now it is going past the immediate present in to an abstract, imagined future, as in the 'chronobiology' of a composition of music, a story without words (Osborne 2010). 
As adults we constantly have to organize ourselves in the present moment to achieve goals that are very distant. Students at university stay in and study to achieve a degree years away, so that they can then achieve a good lifestyle, satisfy their parents, or to achieve mastery of important facts of a very artificial way of understanding. They must organize their present moment - to reach for the phone to call their friend to party, or to grasp a pen to take notes on their assignment. Many of them aimed in the heady days of the 1970 s to go to the moon.

One of the first shared projects of a baby is finding and latching to the nipple for breastfeeding, or sucking a bottle for feeding. Either way the task requires skill, focus of attention and determination to succeed, with shared intentionality. The mother has to align her intentions with that of the infant, to give support and direction and together they form a shared act that initiates toward a common goal, develops its aim of accomplishment, and finally arrives at its goal. When it is successful, satisfaction is realized that can be vital for sustenance and life (Figure 2).
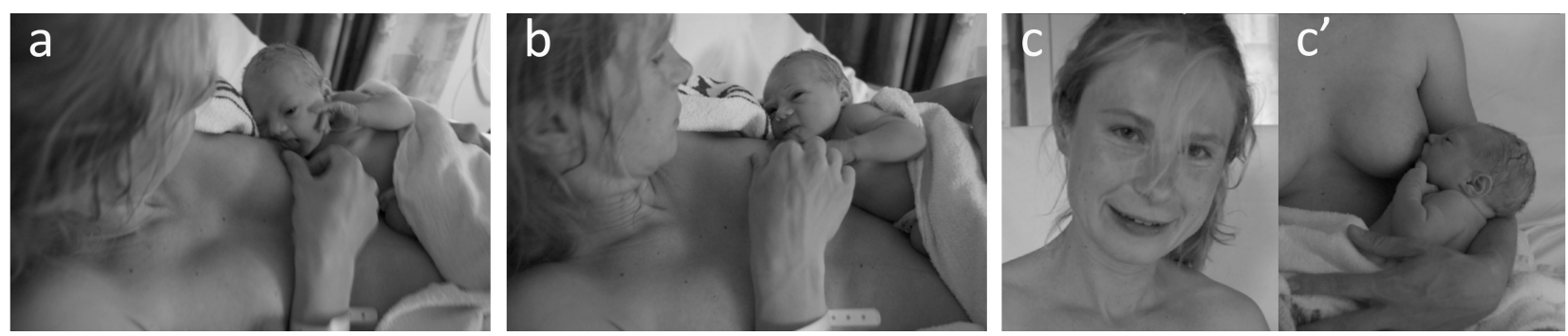

Figure 2. A project shared immediately after birth. A newborn infant is assisted in the task to latch onto the breast for feeding. The project (a) initiates as the infant struggles to latch to the nipple, (b) develops over repeated small movements of mother's hand and body and baby's head, mouth, and arms, coordinating their interest, arousal, and intention with shared eye gaze before (c) the mother and baby reach completion of their project, delivering both psychological and physiological satisfaction, both of which are required for life to progress in mental and physical health.

Sometimes it requires professional support to nurture and soothe the mother after the complex experience of childbirth, and to sooth the infant, and to give them both the psychological space needed for joining together in happy and healthy companionship. This becomes the important task of midwifery or grand-parenting. Sharing satisfaction or joy in the successful acts of cooperation is fundamental to learning the tasks of our human nature. 

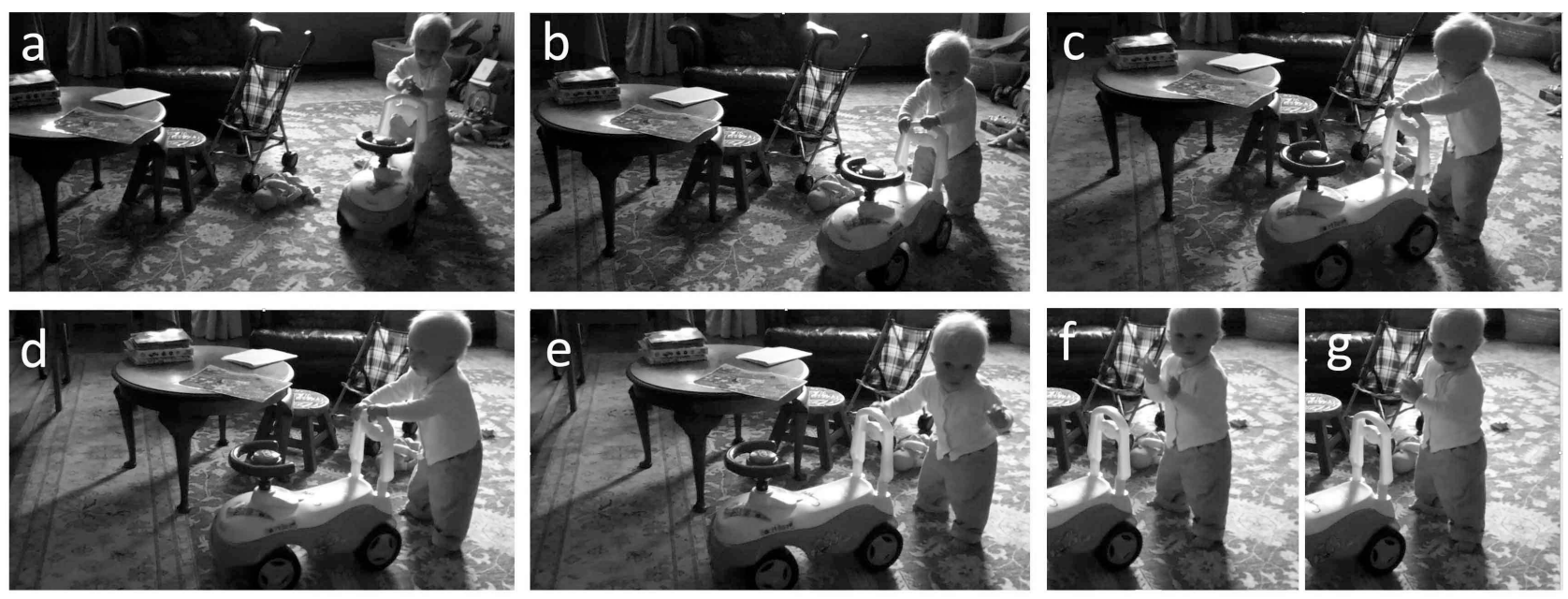

Figure 3. A toddler performing a short project, walking with the help of a push-

truck. The project (a) initiates with attention to the task and (b-d) develops over repeated steps one in front of the other, maintaining difficult shifts in balance with support from the truck until (e-g) final conclusion accomplishment shared with delight and applause with her father filming.

Learning to walk is postponed during infancy, and is a very difficult task for a beginner under one year, putting one foot in front of the other, stepping on something firm and keeping a heavy body balanced (Figure 3). These steps are each organized by their primary goals putting one foot forward, and are repeated over cycles to form a project that takes the toddler further into the future. They form a project, and on their completion, they generate a sense of satisfaction and joy that is both intrinsic to the individual, and can be shared in pride with others (Figure 3).

The Russian psychologist Nikolai Bernstein, who gave us the first scientific proof of 'prospective control' in all kinds of body movement, shown by his very detailed analysis of the forces involved, that an older toddler plays with the agile body, "testing the degrees of freedom" of elaborate motor activity - running, skipping, hopping, jumping and twirling - to master its risks safely and with crazy joy, rarely losing balance or making a false step (Bernstein 1967). A bit older and the child is turning graceful cartwheels through the air like a gymnast. Each of these is a project learned, a project accomplished, and a project to be shared

You see this in toddlers' games of all kinds. The joy at the conclusion of the project, with those motivations and bodily feelings, ensures it will be remembered and repeated, "Again! Again!" (Featherstone, Beswick, and Louis 2008), echoing the delight of children playing in the playground, and their natural desire to repeat the success of their project - sliding the slide, climbing the wall, spinning the round-about. This love for challenge and successful accomplishment is embedded into 
our experience and our learning with its affective, cognitive and motor dimensions. This is how human consciousness, human intelligence in action, is generated.

It begins with its own agent power, affectivity and motor intentionality in the late fetus and early infancy, and in early childhood it invites us to enjoy doing and sharing hugely complex projects which mark us as different from the non-human primates. This is the motivation for the 'working theories' of young children and for their support by understanding teachers described in this book by Sally Peters, Keryn Davis' and Ruta McKenzie (Chapter 16).

\section{How feelings and intentions are shared}

We share what we do and what we know through expressive movement of the different parts of the body that together convey feelings and intentions. Dr. Lou Sander found they are coordinated from birth between mother and infant in one time and space with different modalities of sensation (Sander 2008). This is the message Colwyn Trevarthen shares with us in his diagram of the modalities of two brains and two bodies - two embodied consciousnesses alive -- two 'subjectivities' in communication, mother and baby becoming a companionship in a single artful and sympathetic 'intersubjectivity' of 'proto-conversation' (Figure 4) (Bateson 1979; Trevarthen 1995; Trevarthen et al. 1998)

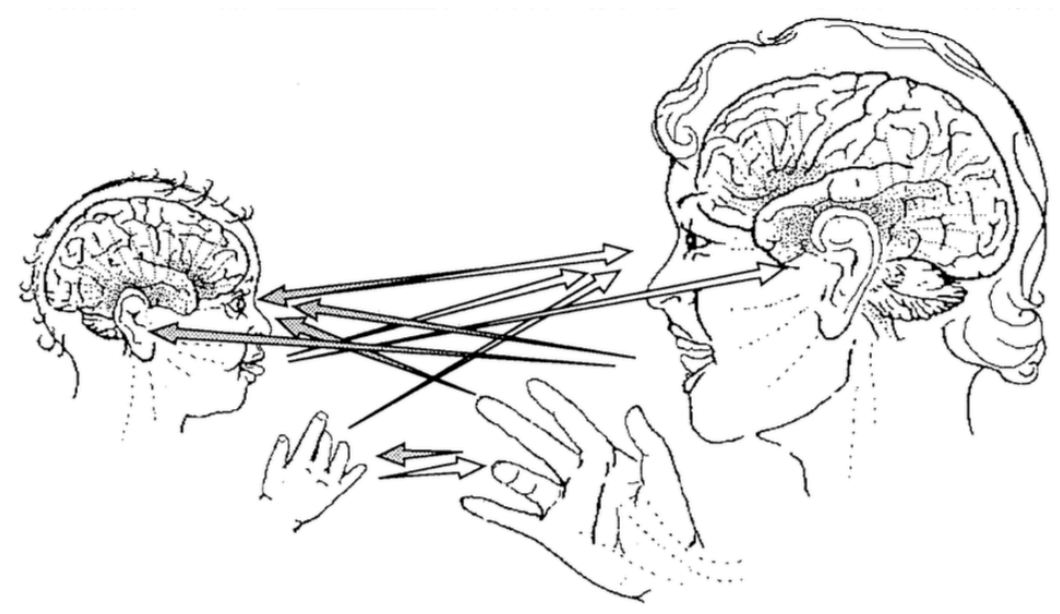




\section{Figure 4. Two people with two brains and two bodies connected in}

intersubjectivity. Feelings, intentions, and desires expressed with body gesture and posture, facial movements, and movements of the voice are received and reciprocated by the other with sympathy, creating altogether a musicality in the rhythms and shared quality of expression in the exchange. From Aitken and Trevarthen (1997).

The hands, the nose, the ears, the face, all interact in harmony to couple the experiences of one person with the experiences of another. The brain functions of one person conveyed in movement are sensed directly by the brain functions of another. This is the collaboration of two persons' 'external synapses' (Bernstein 1967) that connects the experiences of two brains together, that brings two minds together to work as one. We have billions of synapses within our brain that connect one neuron to another, but this is the external synapse of a social engagement, the actions of one particular nervous system interacting with the actions of another nervous system, and importantly those nervous systems are human 'people', not just information-processing organs. This enables an intimate co-operation from birth and shared meaning, sympathy and understanding to grow in sharing experiences, feelings, and intentions. The mothers' feelings, interest, arousal and action, and the baby's feelings, interest, arousal, and action work together in sympathy within a reciprocal relationship where the actions of one side are appropriated, felt by the other, and responded to, again with feeling.

Templates of intimate intersubjective engagement are alive between teacher and pupil, caregiver and child. They structure and pattern our intentions and learning, generating trust in the companionship of shared projects. From the start these events are composed in cycles, as when a mother and her newborn are satisfied in breastfeeding. Or when a toddler completes her first steps in walking, or when a child climbs then slides down the playground chute, or when an adolescent learns a new mathematical equation in dialogue with her teacher - each of these successful acts completed will be repeated again, again, and again, generating stories of experience and discovery then remembered, and learned from.

This is the active foundation for more complex, cognitive cultural intelligence, using symbols in language and the logic of practice. Karl Lashley summarized the importance of understanding the ordering of movement as a route to understanding the nature of human intelligence and communication,

"There is a series of hierarchies of organization; the order of vocal movements in pronouncing the word, the order of words in the sentence, the order of sentences in the 
paragraph, the rational order of paragraphs in a discourse. Not only speech, but all skilled acts seem to involve the same problems of serial ordering". He says "Not only speech, but all skilled acts seem to involve the same problems of serial ordering, even down to the temporal coordination of muscular contractions in such movement as reaching and grasping. Analysis of the nervous mechanisms underlying order in the more primitive acts may contribute ultimately to the solution even of the physiology of logic.” (Lashley 1951, pp.120-121)

This is the organization of our actions and projects, and what becomes more sophisticated in narratives, or stories that unfold over time (Delafield-Butt and Trevarthen 2015). Narratives progress with initiative towards a goal, which builds in intensity as the project proceeds, reaching a climactic point with maximal tension and excitement, then releasing that tension to conclude and appreciate the effect of that activity. All the time-based arts share this four-part narrative structure with its rise in excitation and release, through 'introduction', 'development', 'climax' and 'resolution' (Figure 5).

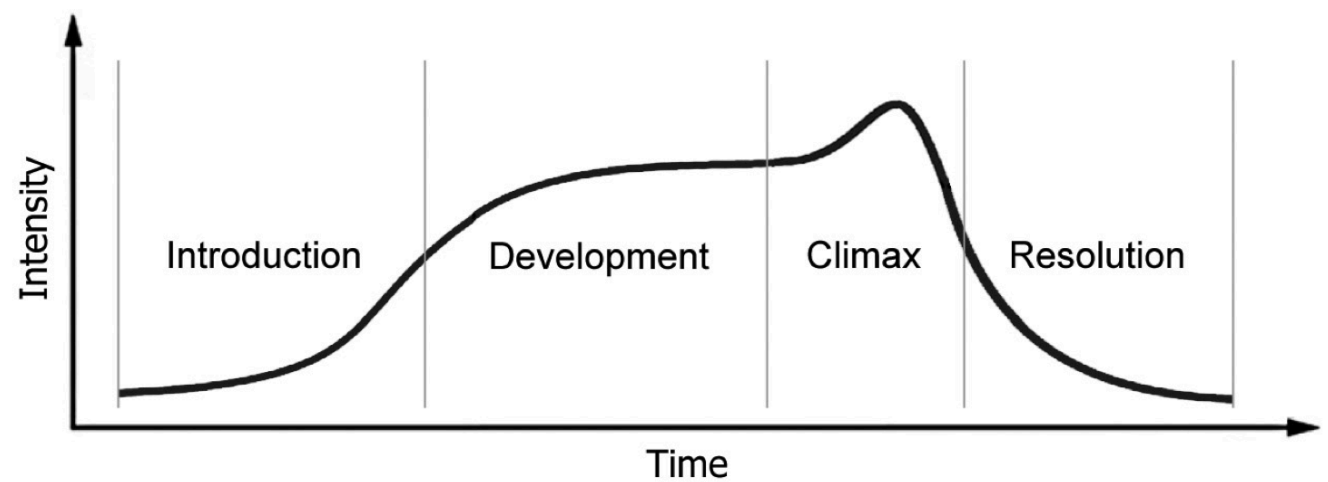

Figure 5. The intensity contour of a narrative over its four phases: (i) 'interest' in the narrative begins at a low-intensity in the introduction, which 'invites' participation in purposefulness; (ii) the coordination of the actions and interests of real and imagined agents intensifies over the development, as the 'plan' or 'project' is developed; (iii) a peak of excitation with achievement of a goal in mutual intention is reached at the climax; after which (iv) the intensity reduces as the purposes of the participants share a resolution, and those who were closely engaged, separate. From Trevarthen and Delafield-Butt (2013a).

This is the psychological and motor organization of an agent acting to achieve something in the future, and our understanding of how actions are organized serially together. It may be an 
instrumental project to do something practical such as cook a fancy dinner, or to go to the moon, or one made artfully to appreciate the grace and excitement of acting or performing, or in the sympathy of a caring other to relieve pain, sadness or loneliness. All our intentions for communication have the same hope and form through a prescribed space and time of moving.

We generate these narratives together in the lived time of intersubjective co-creativity. Narrative are alive in the dynamic and embodied purpose of coming together socially, it is only later they become written or told in a book or verbal story or a musical composition. The lived experience on which those stories reflect are not pre-scripted, but generated in the natural flow between parent and infant, between friends, and between teacher and pupil. And it's co-created on a basic physiological substrate, which is the substrate of our body, the substrate of our affectivity, and its particular temporal and spatial dimensions. We parse our actions taking turns, to create something woven together, co-created between two or more individuals, to make a story in which each expresses a personality for others' appraisal (see Bruner 1996, on the importance of narrative for education).

\section{Learning to regulate the arousal of interest, from birth to school}

The regulation of arousal and interest, in children and their teachers, is a fundamental capacity to master for school learning. Learning this skill is first evident within the co-regulations between infant and mother (Delafield-Butt and Trevarthen 2015), and in children learning to regulate their attention and interest in school (Delafield-Butt and Adie 2016), both structured by their shared narrative form. I will give three examples to illustrate this and the ways instrumental learning can be combined, first from infancy and then in early childhood education.

Baby B, was born prematurely at 27 weeks, one of a pair of twins. He had intensive care in the hospital neonatal unit, and his mother visited every day for sessions of body-to-body 'kangaroo' care, helpful for the development of a premature baby. A recording was made when the mother and her infant had been in hospital for 8 weeks, and B was healthy and due for discharge.

Figure 6 shows how lively Baby B was with his mother as she spoke and attended to him affectionately. He made many arm movements which were recorded (Fig. 6a), and we plotted these with the pitch plot of the vocalisations they exchanged (Fig. 6b). The transcript of what the mother said (Fig. 6c) puts words to their feelings and expressions as they develop a story of their experience together.

Their contour of excitation and arousal in engagement follows that of a drama. It has an 'introduction' that brings the togetherness out of a quiet, quiescent moment, an invitation to a cocreated narrative episode initiated through the mother's vocalization and the infant's contributions. 
These develop over time, with a pulse close to 1 per second or largo, a slow walk, creating peaceful musical elements with shared rhythm and timing. The mother's vocalisations start to increase their pitch and intensity and the baby comes to contribute with all of his energy and his creative apparatus (smile, voice, and movement) culminating in the a moment of peak excitation, a 'climax'. The mother then regulates this arousal with a long, regular descending pitch glide from the top of the octave above Middle $\mathrm{C}$ to below Middle $\mathrm{C}$ (at 11). This descending pitch bring the energy and arousal down and concludes the narrative. In this way the mother can be seen to regulate her baby's excitement at a very sensitive early moment in his life, developing small narrative patterns as a template for regulation and in which meaning can be contextualised. 
a

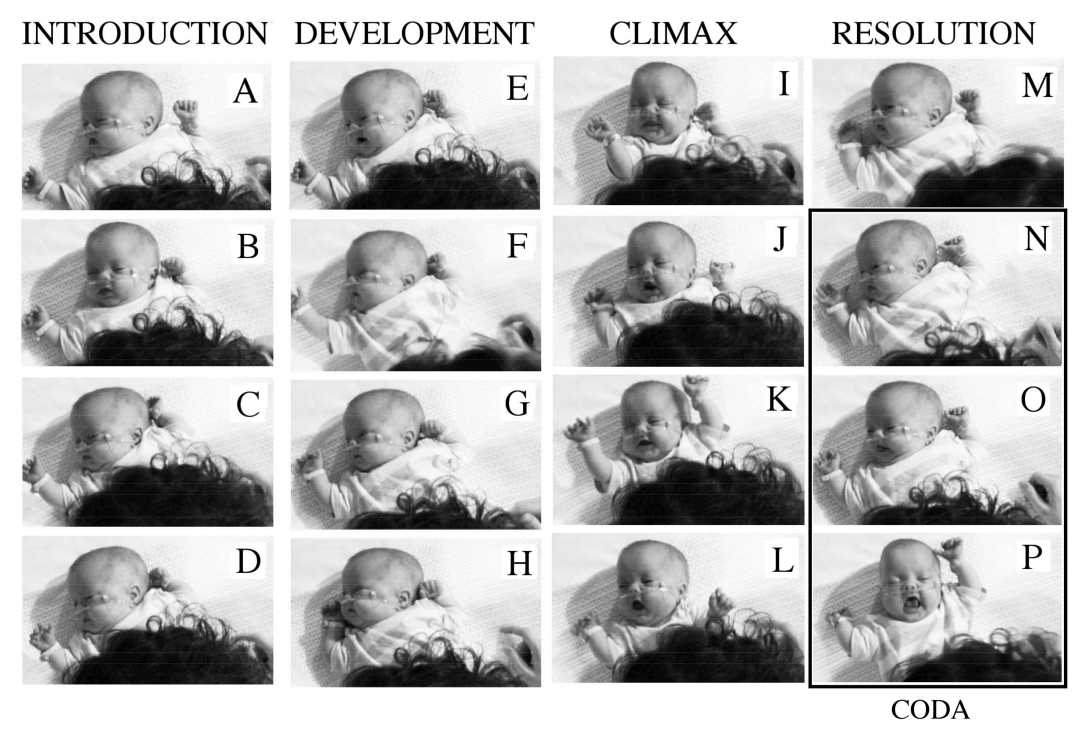

b

A B C D E $F$ G HIJKL $\quad$ M N BABY B'S ARM MOVEMENTS
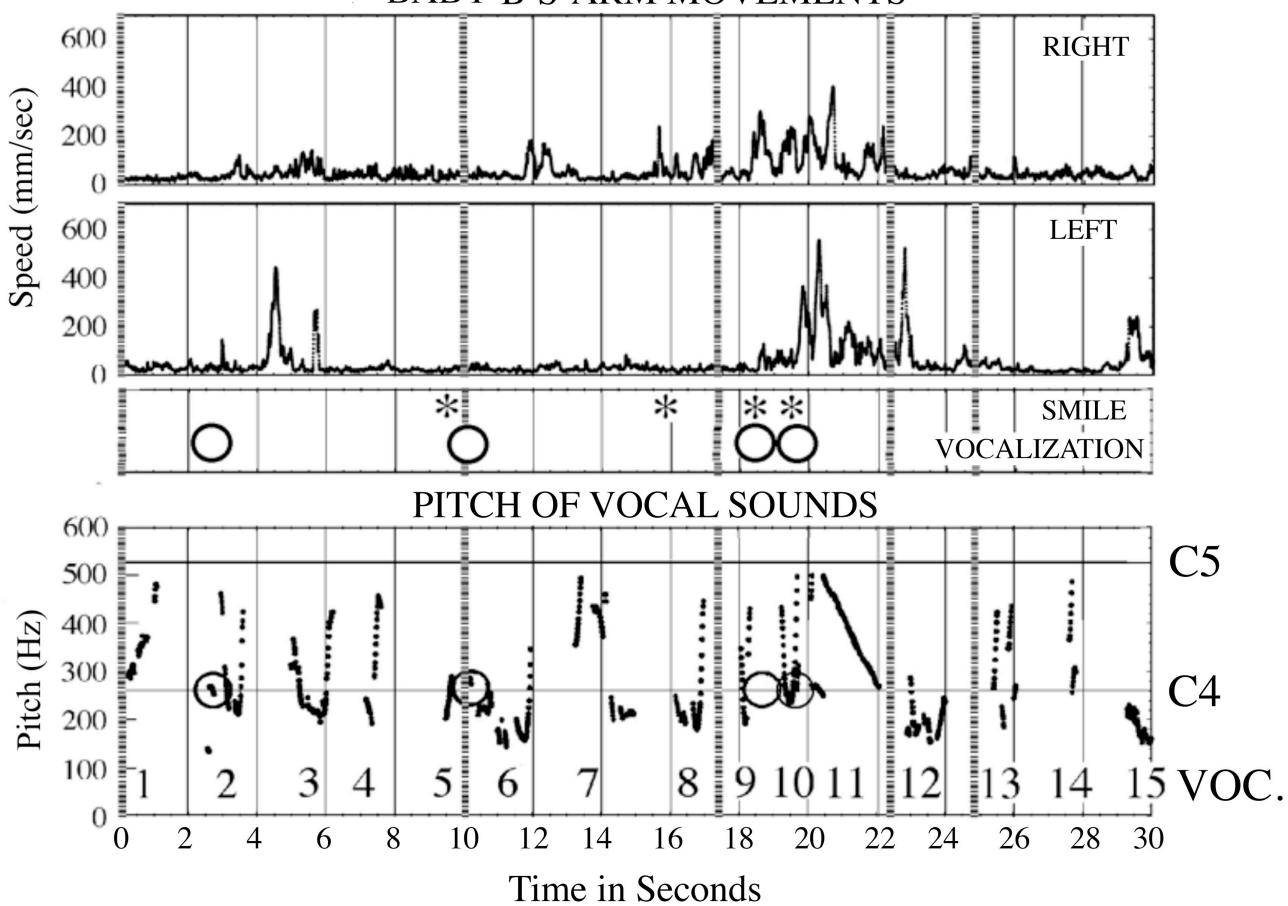

C introduction [AtTENTive] Climax [LiVELY/Engaged]

1 - Are you woken up. mister?

$9-\mathrm{Hi} \mathrm{Ya}$ !

2 - Good afternoon!

10 - Hello there!

3 - Good afternoon, wee B.

11 - Kiss and Glide

$4-$ How are you doin'?

$5-$ Eh?

RESOLUTION [REFECTIVE]

[RELAXED]

DEVELOPMENT [RESPONSIVE]

$12-$ Oh, you're kicking your Mum.

6 - Oorh, look at that big smile!

$7-[O h$... That's all great]

13 - Are you kicken me?

8 - Look at that big smile.

$14-$ Eh?

15 - Have a big wriggle, then. 
Figure 6: An early embodied narrative between a young prematurely born infant and his mother demonstrating its embodied, co-created four-part structure.

(a) Video stills show the expressive actions of the upper limbs, head and face at different moments in interaction. The columns correspond to the four phases of a narrative of purposes and experiences supported by the vocalisations of his mother.

(b) Speed of Baby B's arm movements recorded with motion capture cameras are given in the top two graphs, with smiles and attempts to vocalize marked below. The mother's speech is given in the final pitch plot of 30-second dialogue. Baby B's own voice was too hoarse to register a pitch, but mother's encourage upward glides can be seen to give rhythmic structure and positive energy to the interaction within the octave above middle $\mathrm{C}$ - the area of positive affect. Along the top, the locations of the photographs shown in (a) are shown by letters A to P. At 11, the mother bring the climactic energy down with a descending pitch glide to settle her baby again, before the whole narrative concludes. (c) A transcription of the mother's speech and vocal expression. The utterances are numbered and identified in the pitch plot above.

Photographs N, O and $\mathrm{P}$, and utterances 13,14 and 15 are boxed to indicate that at this phase B is recalling the narrative event in a coda, as his mother's speech gently encourages him. Reproduced from Delafield-Butt and Trevarthen (2015).

Baby B's mother is trying to regulate or to help him, saying what she is thinking about helping to regulate B's excitement so they share the conclusion where she is calming that activity and bringing quiet again. Then they have a small repeat of the story, a small coda as in a piece of poetry. The whole piece has a narrative contour - the intensity rises in the introduction, continues to rise over repeated phrases of this development, until a peak moment of excitation or climax and then the resolution. They make a shared meaning, now held as memory that can serve to structure the next, future meeting.

\section{Intersubjective resonance of intentions and feelings, how brains link vitalities}

This engagement between Baby B and his mother illustrates how affects, feelings and intentions are conveyed in movement. Advances in brain science confirm our understanding of the shared consciousness required for intersubjectivity, before a more rational 'theory of mind'. There are two systems responsible. 
The first is the 'mirror neuron system' discovered by Giacomo Rizzolatti and colleagues in Parma 20 years ago (Rizzolatti and Gallese 2003). It is a very important system that appears to be responsible for organizing the actions of the individual, while also serving to recognize those same action performed by another person. During observation of others' actions, the neurons produce a direct 'resonance' between individuals - the same system is active in both the actor and the observer. In psychological terms, this gives us a basic, implicit understanding of the intentions of the other, so-called 'mind-reading'. This mirror resonance precedes mentalising, or higher cognitive capacities. It is not necessary to reflect on such sharing or to think about it. No 'theory of mind' is necessary. It is intuitive knowledge of another person's intentions available by correspondence with the motor intelligence of our nervous systems (Sinigaglia and Rizzolatti 2011).

There is another system of the embodied mind important for sharing feelings and intentions directly between individuals, without words. It brings our attention back to the brain stem and originates in the functional regulation of feelings of vitality inside the body. This is the 'polyvagal system' identified by Stephen Porges (2011) of the University of Chicago. He describes this as an evolutionarily advanced system in humans that allows us to share regulatory control of breathing, heart rate, and the energy we need for healthy and expressive body movements (Porges and Daniel 2017).

Porges found that vital autonomic physiology controlled by the ancient vagal nerve, which evolved for visceral motor control of feeding, respiration and circulation of the blood in primitive vertebrates that had little capacity for imaginative life and social cooperation has been transformed in evolution of mammals to afford a rich intersubjective coupling (Porges and Furman 2011). These autonomic organ systems and their adaptation to plans for action are coupled in the brainstem to become an enriched social engagement system that regulates the intonation in our voice and the expressive character of our hands, fingers, and facial expressions. Porges discovered our vital autonomic physiology is directly coupled to expressive gestures and vocalisations, which gives us the powers of what Thomas Reid calls our 'natural language.' Because these expressions announce our vitality, our wellbeing, and how active, energetic, aroused, interested we are, as well as what we need as physiological organisms, they are the foundation of the skills and resources we may learn. They enable us to be together in any shared intersubjective space, such as the classroom, to perform tasks together in mutual understanding and enjoyment.

What this allows us to do is directly regulate our autonomic systems, our physiology, one to the other, without thinking about it. It's a feature of shared, pre-reflective primary consciousness (Trevarthen and Delafield-Butt 2017). So, altogether we feel each others' feelings, vital feelings, in their primary intentional acts, which is what Dan Stern described as 'forms of vitality' (Stern 2010). 
Within the dynamic between subjects, a musicality is formed between feelings expressed with shared timing and reciprocal qualities of voice and gesture (Malloch and Trevarthen 2010).

Developments in the cerebral cortex enrich this sympathetic sharing, but the critical evolutionary change is in the brain stem, cerebellum and midbrain where basic forms of expressive movement and rhythm are generated and regulated in body-related ways.

\section{Co-created narratives become social schemas with significance}

Baby B's narrative projects co-created with his mother's sympathy are also recognisable as goaldirected projects. They aim towards something, they build as the act proceeds, they come to a climax of maximal tension and then release into a conclusion. In many cases of human relating the goal that is planned is one of mutual understanding. When you meet someone in the street and have a chat, you initiate and develop recognition, you shake hands, chat about this or that, gossip, and make small talk. It may be irrelevant what you're talking about, the goal is manifestly to attune, and then when you're happy, you are satisfied. You say your farewells and off you go to the next project or to continue what you were occupied with before you met.

Such schemas for interpersonal encounters can grow into the habits and recognised rituals of a culture, and their styles will differ. With Koichi Negayama, a child psychologist from Waseda University near Tokyo we have studied the differences between protoconversations of Japanese and Scottish mothers and babies. Using methods of motion capture to track gestures, expressions, and movements of the body we found that Japanese mothers follow their babies and wait for the baby to initiate an engagement (Negayama, Delafield-Butt, Momose, et al. 2015). Even in a task as simple as picking up her baby, a Japanese mother will wait for the baby to take the initiative. A Scottish mother, in contrast, tries to lead or coax her baby, moving on and sexpecting her baby to follow. If the baby is not following, then she tries many tricks, rattling a toy to attract attention, making an aeroplane of the spoon to get her baby to join her project. This is a difference in cultural expectations of how to behave, and how a child should respond. In any case it is about expectations and anticipation and what we intend to do, both positive and negative. We become encultured into a particular society with its expected patterns of behavior that are built on these early rituals of companionship and the value we give to agency within it.

\section{Learning social schemas that enable learning}

Frederick Erickson, Professor of Anthropology of Education at the University of California, gives examples how shared narratives of learning, using prosody of expression to support interest and 
achievement, help participation and the grasp of conventional ideas of reading writing and arithmetic in school (Erickson 2010). He describes musicality in talk and listening as a key element in classroom learning. Narrative patterns acive in the school classroom with their non-verbal musical structure enable supportive, guided instruction. I give two examples of the use of these principles to help students who find regulation of their arousal and interest difficult, and who therefore struggle with learning in the classroom. By learning the pattern of co-created narrative, they can find the confidence to cooperate with teaching, and enjoy learning.

\section{Nurture Group guidance of affects, interest and attention to numeracy}

In a special school classroom, called Nurture Groups, children are helped who find the habits of the mainstream class difficult. These children find it difficult to regulate their attention, arousal, and his interests to match the intentions of the teacher and wider school system. In a mainstream class they often cannot sit still and find it difficult to integrate socially meaningfully. These children, with so-called social, emotional, and behavioural difficulties, can become a problem for an educational system intended to prepare them for life in a harmonious, intelligent, and sophisticated society. It is assumed their problems arise due to difficulties in early family care. Nurture Groups employ techniques of mothering, techniques to work with the emotional and social development of the child to nurture confidence, and to generate more positive attachment relationships.

Together with $\mathrm{PhD}$ candidate Jillian Adie we analysed the intersubjective patterns of engagement between these teachers and the students. We found the same narrative pattern of embodied, affective engagement evident between caring adults and their younger children, but with a greater degree of cognitive and linguistic skill included (Adie and Delafield-Butt 2016; Delafield-Butt and Adie 2016). In this example, a child in a Nurture Group was helped to share the walk down stairs (Figure 7), a simple task that a teacher may dismiss as irrelevant to the purpose of education, but that served as an important experience of shared learning - affective and cognitive - giving confidence as well as knowledge. 
a

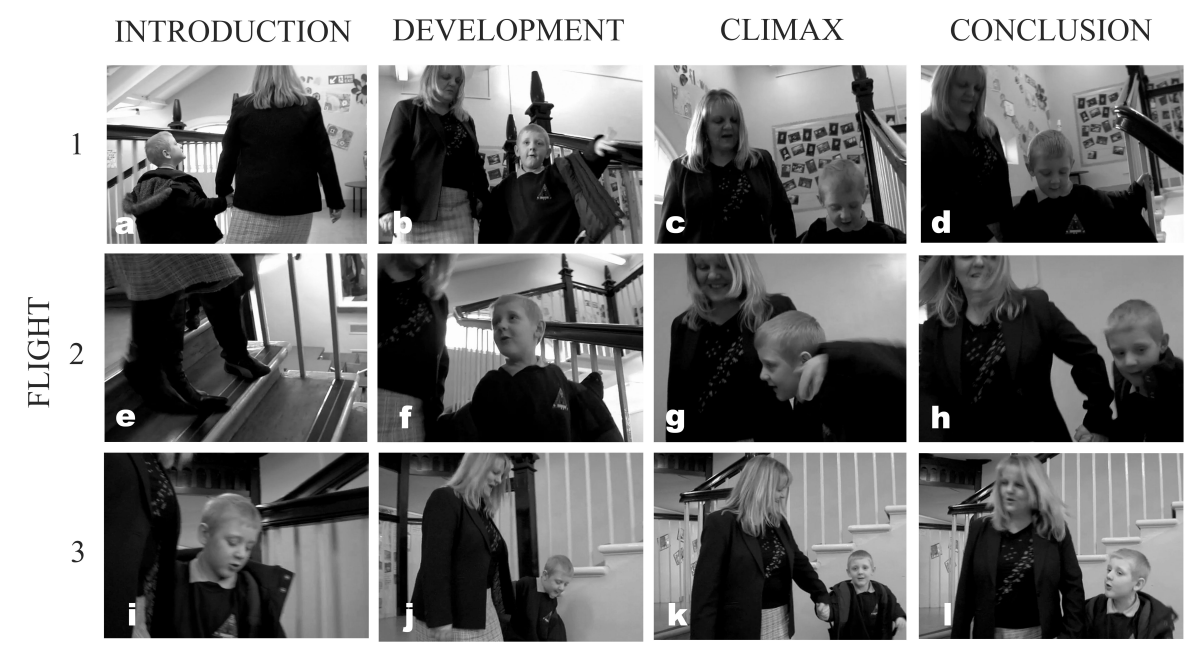

b

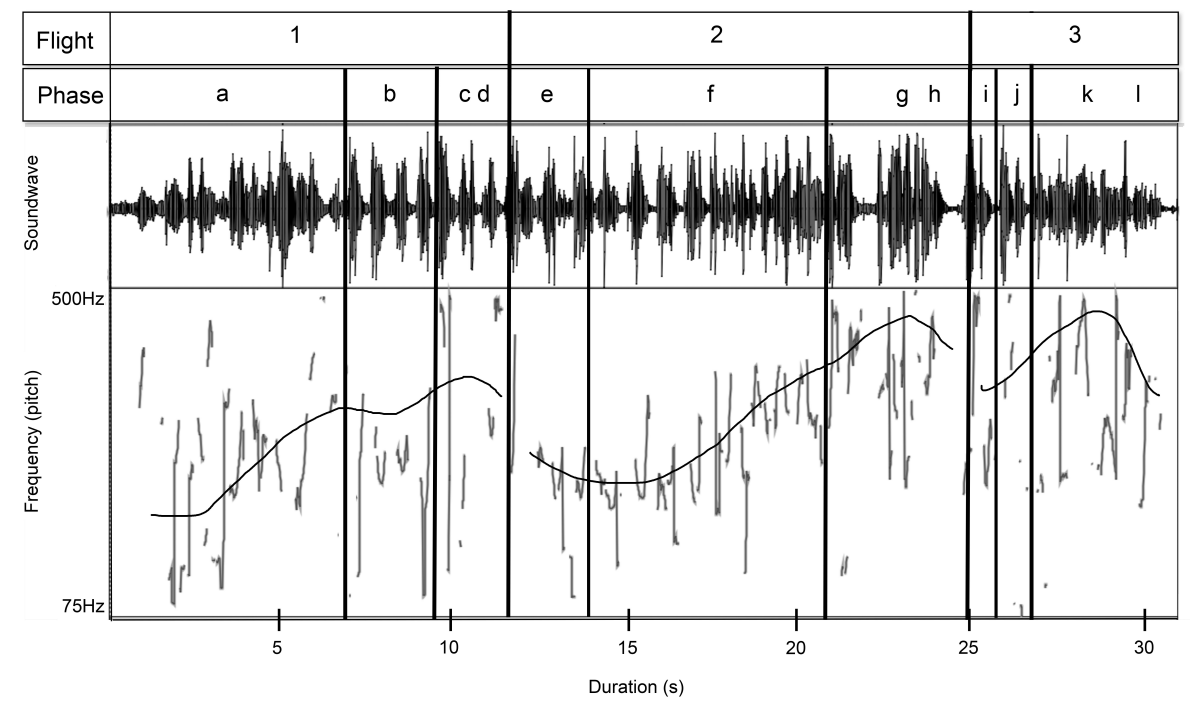

Figure 7. A co-created narrative project in school, made while descending the

staircase and counting. (a) A picture board illustration (top rows) organised by its three episodes of descending the 3 flights of stairs. Each episode displays the four phases of introduction, development, climax and conclusion. The conclusion is tight in between flights with little time to relax, the task demanding immediate preparation for the next flight. Though conclusions are short, the climax of accomplishment in each phase is clearly noted with smiles and increased pitch of the voice signalling delight. Eye contact is made. (b) The sound wave shows marked rhythmicity of vocalisations by teacher and student. The sound wave spikes indicate footfalls on the steps. The pitch of each vocalisation is calculated (frequency, Hz) and plotted. The full dyadic structure of childteacher interaction over the course of the three flights displays a narrative pattern of 
intensity and progression as the pair move through the phases of introduction to the task, development of rhythmic shared interaction as they descend the stairs together, a climax as they share simultaneous joy on reaching the bottom of the stairs, and a conclusion of the activity as they leave this activity behind to commence something new. Narrative contours (black) approximately overlay the rise and fall of vocal pitch to deliver one over-arching narrative with three narrative sub-units that correspond to each flight of stairs. The phases are as follows:

(a) Introduction as the teacher structures the opening of the interaction, explaining the task ahead as they walk towards the top of the staircase. (b) Development as they descend the first section of stairs, their footsteps falling into rhythm as they count the stairs together. (c) A small climax marked by excitement in vocal pitch as they reach the first turning, quickly (d) concluding and leading straight into a limited (e) introduction to the next task as they negotiate this first turning and make their way to the second flight of stairs. (f) a second development begins as the child looks to the teacher as she counts the stairs aloud to reestablish their rhythm and (g) smiles as they share understanding of their collaborative activity, bringing a second small climax, this one larger than the first, as they reach (h) the end of the flight of stairs and turn, concluding this episode as they begin to negotiate the second turning, leading to the final sub-narrative. They (i) introduce quickly the final episode and (j) develop this task by concentrating together on its completion as they descend the final flight of stairs before (k) they share a final climax of peak satisfaction and joy as they reach the bottom, the teacher smiling as the child lets out a whoop of joy. The piece (l) concludes as they leave the staircase behind, now quiet, and head towards a new activity, content with their accomplishment. Adapated from Delafield-Butt and Adie (2016).

In the recording, he enjoyed the planned participation and on its conclusion was delighted with their accomplishment. The teacher held his hand and took him down the stairs. They moved rhythmically, and musically with a basic non-verbal narrative structure, and they adding counting the steps, bringing in maths, something very abstract which requires a conceptual intelligence, to understand what it means.

The pitch plot of the video shows how the recitation rises and falls through the different phases the first flight of stairs, the second flight of stairs, and then the third flight of stairs. The teacher's voice rises and falls as the project unfolds through three sub-narratives or sub projects that make one 
whole narrative or project. As the child completes the final flight of stairs and lets out a 'Woo hoo!' before it concludes, a special moment before they go off to do something else. The child has shared something intimately with the teaching, holding hands a sharing their affectivity, and has learned something about what numbers mean, what they can mean with another person, the value of those numbers as socially meaningful fun. This catches that child's interest in numbers and in thinking, with the regulation of arousal and attention, and attracts his intentions that will be required to learn more about those things in a mainstream class.

And after one year of this kind of activity, as little as half a day a week, the children are typically ready to go back into mainstream school. This kind of special education becomes very important, improving the basic psychological skills to succeed and school education, thereby improving the life-long opportunities for each child and significantly reducing burden to society (Boxall 2002).

\section{Learning expectation and arousal in the narrative of a game}

Finally, we draw our discussion of the importance of embodied, non-verbal narratives in education to a close with a second example of guided participation in a Nurture Group (Figure 8). Once again this is an account of a narrative with a contour, that exhibits the escalation of intensity of expectation until the climax of delight, "Yeah!" at the end. And then quiet, from which another narrative can unfold. We see the rhythmicity, this time becoming much more complex with intrusions from the other children and other teachers, but that maintains its coherent form over the act. The same principle this basic act serving to stimulate confidence and repetition of the project acts as a bedrock on which higher cognitive intelligence and the stuff of older classroom learning language, literacy, numeracy, and maths - can be firmly secured. 

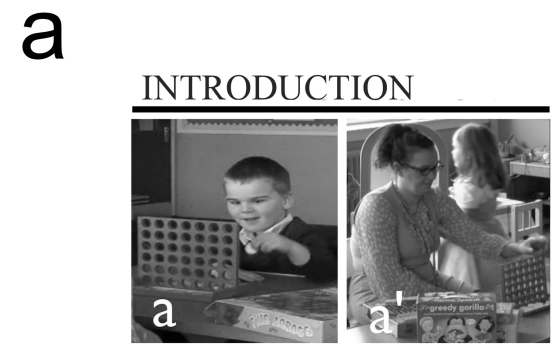

DEVELOPMENT
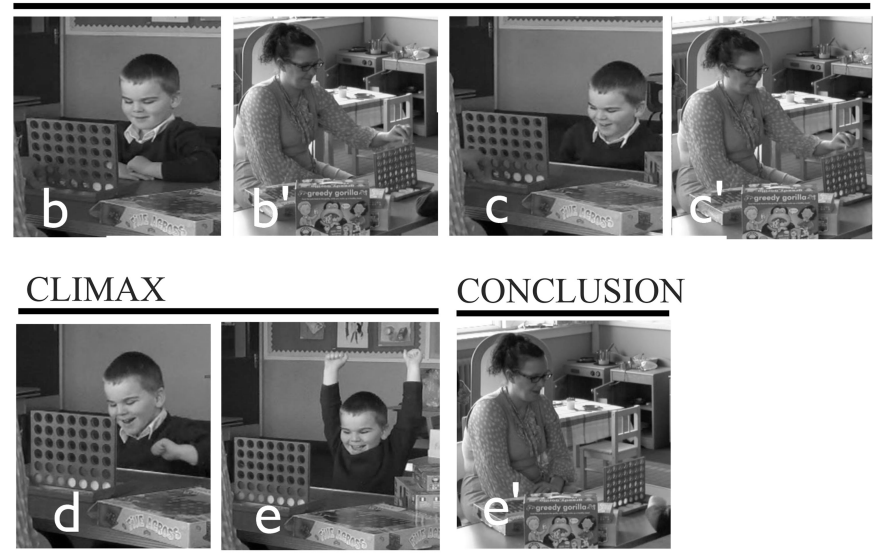

b

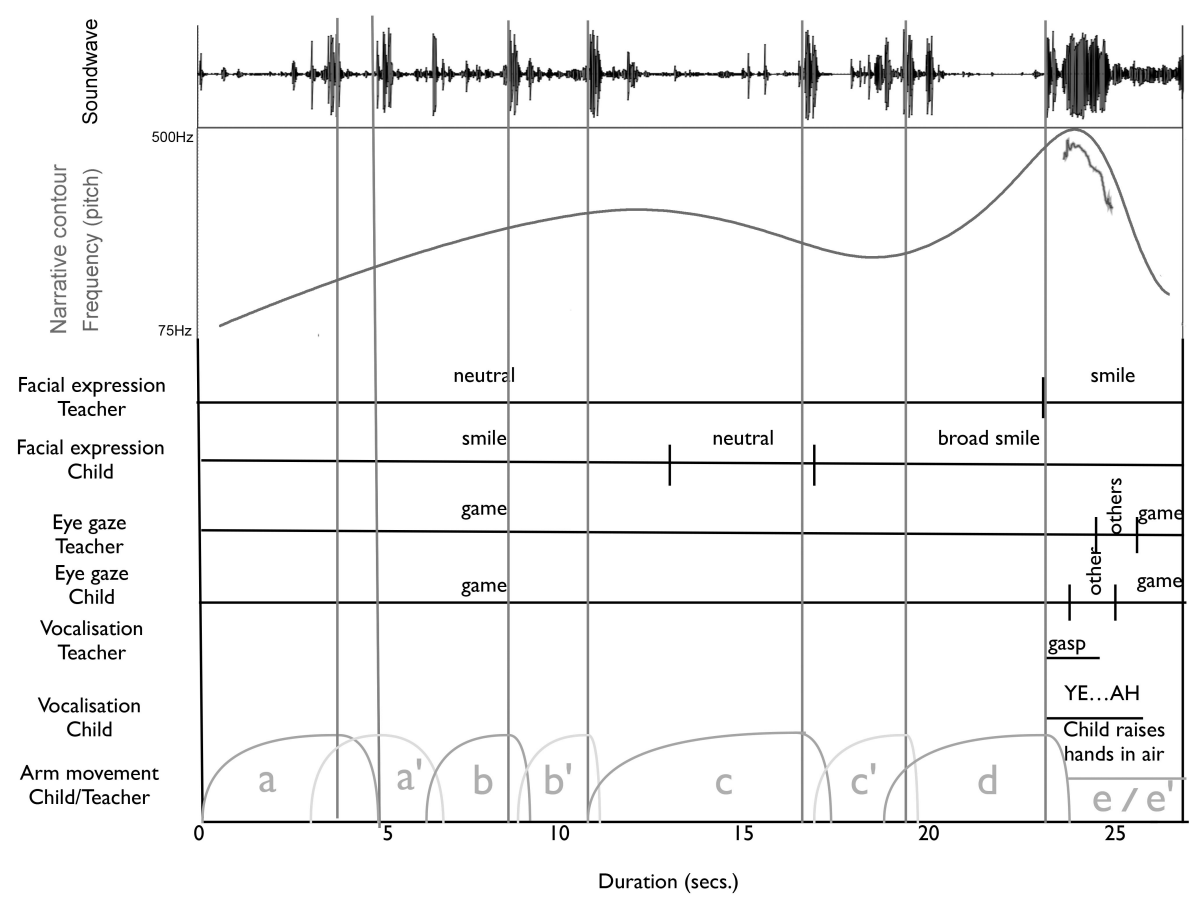

Figure 8. The embodied narrative of dyadic child-teacher Connect 4 gameplay. The soundwave indicates the fall of the tokens into the game, together with background classroom noise. Accoustic frequency of vocalisations is registered only at the final vocalisation of "Yeah!" by the child - no other vocalisations were made. The narrative contour of intensity approximately follows the combination of vocal pitch, facial expressions of teacher and child, eye gaze, gestures, expressions, and teacher and child 
vocalisations. The narrative develops through cycles of gameplay turn-taking. The child's turns are identified by the action curves $\mathbf{a , b}, \mathbf{b}, \mathbf{d}$, with the teacher's corresponding turns identified a', b' and c'. Each action curve indicates a reach-grasp-drop - the drop indicated by the red vertical line segmenting the piece - and final return of the hand to the table. The climax to the interaction at e/e' is identified by the child's high pitch exclamation, "Yeah!", at the top of Middle C with a downward glide as he simultaneously throws his arms in the air and the teacher takes a sharp inhalation of breath. The child and teacher are attentive to the game throughout while recognising it as part of a greater social interaction as they share their joy with the other teacher (other) in the room on completion of the game. Reproduced from Delafield-Butt and Adie (2016).

\section{Narrative intelligence and feelings in the foundation of cognition}

I have been describing the development of what Jerome Bruner calls 'narrative intelligence', a form of learning and exploiting the lawful relations between events of people and things and knowing their vital life consequences. This form of intelligence, built on embodied participatory experience of the affective agent, stands in contrast to what he calls a 'logico-scientific intelligence', a conceptual and abstract intelligence that we typically think of as being 'clever', as in 'clever clogs' clever (Bruner 2003). Narrative intelligence is predicated on process, the way things unfold over time in relation to each other. It also described as the 'line mode' of the human mind identified by Margaret Donaldson (1992).

A story proceeds through time and space, and therefore is embodied and affective when we create it, in contrast to the logico-scientific or 'construct' mode of concepts that are static and disembodied 'somewhere, some place'. It is built on the structure of experience and it is always coloured with this vital affectivity, which is difficult to get rid of. In fact we do PhDs as a form of scholarship designed to get rid of feelings, to be purely logical and rational, without admitting that affectivity or subjectivity necessarily contributes to form our intelligence.

Logico-scientific intelligence is built on experiences that have to occur within the motivation of a narrative intelligence. And they must be fed back through that narrative intellect to be shared with others in communication, whether written or oral, and this then means the affects with their socialemotional or poetic value systems are again placed ahead of 'pure' logico-scientific intelligence. This is why although we can know facts and figures we use the intelligence that is lived in the body and in the moment of our actions to explain the truth in the cause of our vitality, to find the natural basis of common sense. "It is by natural signs chiefly that we give force and energy to language; 
and the less language has of them, it is the less expressive and persuasive" (Reid, 1764/1997, p.106-107).

Logico-scientific thought gives us a wonderful abstract world of generalized facts, but they require animation. As Albert Einstein understood, even the laws of physics are stories told about imagined actions in experience. Likewise a legal trial is as Jerome Bruner said, just one story versus another and neither are true. That is why he chose to end his career as Professor at New York University School of Law. He wanted to understand how law is about values, what is just and what is unjust, what is criminal and what is not. And his long life had been devoted to understanding how we and children are motivated to educate and be educated in shared beliefs and values.

\section{Autism, reduced motor control and need for attunement in intentions with affection}

Before concluding, I will mention recent ideas about disruption to primary experience in autism spectrum disorder to explain how it affects a child's communication and learning. Autism is a very particular childhood disorder with social, affective and cognitive aspects (Kanner 1943). All these aspects of the human mind are expressed through movement, as we have seen. It is now clear there is a subtle, but significant disruption to the physiology of motor control in children with autism that may be a core part of the disorder, evident from birth (Fournier et al. 2010).

Teitelbaum, Teitelbaum, Nye, and others (1998) first recorded movement differences at birth in infants that later develop autism and since then researchers such as Profs. Nicole Rinehart and Jenny McGinley in Melbourne have worked to characterize and better understand these movement differences in children (Rinehart et al. 2006; Rinehart and McGinley 2010). Using an iPad to record children's movements as they played a game, we recently found we could identify with 93\% accuracy whether or not a child has autism simply by analyzing their movements (Anzulewicz, Sobota, and Delafield-Butt 2016), a result that underlines the significance of the disruption in autism, and that is corroborated using similar games (Crippa, Salvatore, Perego, et al. 2015).

Evidence of the role of agency in movement in child development indicates disruption to motor timing may lead to a deficit of meaning-making by expressions of the body normally shared in narrative. If the expressive intentions and feelings in movement are confused, this will affect the child's sense of agency and weaken social and affective engagement, leading to secondary consequences of restricted interest, social withdrawal, and cognitive compensations (Trevarthen and Delafield-Butt 2013b). 
The expressive 'instruments' needed for communication appear mis-tuned in autism, with subtle timing differences. In consequence, a typical person seeking communication with a child with autism may not readily understand the intentions, interests, and feelings that generate a movement, because the spatiotemporal pattern of a movement is different. They cannot 'read' these intentions and their expressive agency or message as readily, because typical brains are attuned to standard forms of movement with their expected feelings and intentions.

We read the difference as uncertainty or awkwardness in the child's behavior, and sense a disconnection. Pre-reflective and pre-conceptual awareness of motor intentions is disturbed, part of the direct mind-reading process on which our conscious reflections are based. Therefore, at a primary level of conscious awareness, we find it difficult to read the feelings and intentions of the child with autism as he or she moves. The disjunctions arise between two mis-attuned sensorimotor systems (Delafield-Butt and Trevarthen 2017; Cook 2016).

One way to correct this disjunction is for us - as professional teachers and care-givers - to adjust to the child and attune ourselves differently to the child's actions, so that we can read their feeling and intention, their 'affective vitality', as Dan Stern would describe it (Stern 2010). One way of responding that has proved effective is by imitation, by redirecting our movements to match the child's (Nadel 2014). This can take place in everyday classroom practice to deliberately attune to the child's embodied feelings, or can be developed into techniques for more regular, focussed therapy (Trevarthen et al. 1998; Athanasiadou and Karkou 2017; Caldwell 2004; Zeedyk 2008). Finally, following the child's interests and bringing these into the curriculum for learning can offer another route into the child's awareness and interest, helping to generate intersubjectivity and learning in the co-creation of meaning (Gunn and Delafield-Butt 2016).

\section{Conclusion: Reaching for satisfaction in learning, and making sense of the world with others}

In this chapter, I have addressed topics of embodiment and feeling with emotion important for learning and education. The importance of agency, the power coming to life within the self to engage with the world or with another person. Embodiment, how the form of our body in its muscles and skeletal system, with its visceral cycles of arousal and affectivity, can lead to growth of intelligence as these cycles are made meaningful with other people. This is what is required for making contact. To make contact, the feelings and intentions must resonate between individuals, and then when they do, each action of the self is contingent on, or co-operative with, the actions of 
the other. It is this attuned reciprocity that leads to growth in learning to enable the development of more sophisticated projects. Resonance of purposes and feeling in exchange of movements is essential, otherwise the meaning intended and the complexity we add to it by use of language, numbers and other symbolic concepts, is lost.

When we create narrative patterns of meaning-making as a teacher with a child, the stories must come to conclusion in completeness. This, if done well, generates satisfaction and joy. In this positive sensation of success, or pride, confidence is created, and skill is acquired because the child has confidence and inspiration to do the next cycle with equal or better effect.

All depends on the intuitive foundation of sensorimotor intentionality, first evident in fetal life. Development from primary to secondary to tertiary intentional projects of imaginative action, generating trust in co-action with others, creates shared joy and understanding. It inspires the stories that structure the rituals and games and tasks of our culture. We learn these as children, and we take pleasure and profit by sharing them as the culture of our community. All depends on the embodied narrative intelligence first displayed by a newborn baby.

The urge to share narrative guides experience and knowledge from the beginning of life in projects, such as to touch a twin in utero, to share actions with a mother for breast feeding, or learning to place one foot before the other to walk upright, to more complex projects in social co-operation, such as in learning the rituals of school classroom conversation, or counting. And as these stories become more sophisticated, demanding increase in cognitive intelligence. There are many demands to regulate and attend to - to sit upright, to wear the right clothes, speak clearly, and attend to your homework with correct academic precision. It is on shared meaning as vital, embodied, and affective creatures developed in narrative on which we build all the cognitive, sophisticated, planning capacities that enable us to join in the teacher's imaginative story, and do ambitious, hopeful things - like go to the moon.

\section{References}

Adie, J., and Delafield-Butt, J.T. (2016). Social and emotional development in nurture groups: The narrative structure of learning through companionship. The Psychology of Education Review, 40(2), 3-9.

Aitken, K.J., and Trevarthen, C. (1997). Self-other organization in human psychological development. Development and Psychopathology, 9, 651-675. 
Anzulewicz, A., Sobota, K., and Delafield-Butt, J.T. (2016). Toward the autism motor signature: Gesture patterns during smart tablet gameplay identify children with autism. Scientific Reports, 6. doi:10.1038/srep31107

Athanasiadou, F. and Karkou, V. (2017). Establishing relationships with children with autism spectrum disorders through dance movement psychotherapy: A case study using Artistic Enquiry. In: Daniel, S. and Trevarthen, C. (eds.) Rhythms of Relating: Stories from Children's Therapies. London: Jessica Kingsley Publishers, pp.272-291.

Baldwin, J.M. (1895). Mental Development in the Child and the Race: Methods and Processes. New York: Macmillan.

Bateson, M.C. (1979). The epigenesis of conversational interaction: A personal account of research development. In: M. Bullowa (ed.), Before Speech: The Beginning of Human Communication. London: Cambridge University Press, pp.63-77.

Bernstein, N. (1967). The Coordination and Regulation of Movements. Oxford: Pergamon.

Boxall, M. (2002). Nurture groups in schools: Principles and practice. London: Paul Chapman.

Bruner, J.S. (1996). The Culture of Education. Cambridge, MA: Harvard University Press.

Bruner, J.S. (2003). Making Stories: Law, Literature, Life. Cambridge, MA: Harvard University Press

Caldwell, P. (2004). Crossing the minefield: Establishing safe passageway through the sensory chaos of autistic spectrum disorder. Brighton: Pavilion Publishing.

Castiello, U., Becchio, C., Zoia, S., Nelini, C., Sartori, L., Blason, L., D'Ottavio, G., Bulgheroni, M., and Gallese. V. (2010). Wired to be social: The ontogeny of human interaction. PLoS ONE 5(10): e13199.

Cook, J. (2016). From movement kinematics to social cognition: The case of autism. Philosophical Transactions of the Royal Society of London B: Biological Sciences, 371(1693). doi:10.1098/rstb.2015.0372

Crippa, A., Salvatore, C., Perego, P., Forti, S., Nobile, M., Molteni, M., and Castiglioni, I. (2015). Use of machine learning to identify children with autism and their motor abnormalities. Journal of Autism and Developmental Disorders, 45(7), 2146-2156. doi:10.1007/s10803-015-2379-8 
Damasio, A.R. (2003). Looking for Spinoza: Joy, Sorrow, and the Feeling Brain. Orlando, FL: Harcourt.

Delafield-Butt, J., and Adie, J. (2016). The embodied narrative nature of learning: Nurture in school. Mind Brain and Education, 10(2), 14. doi:10.1111/mbe.12120

Delafield-Butt, J.T., and Gangopadhyay, N. (2013). Sensorimotor intentionality: The origins of intentionality in prospective agent action. Developmental Review, 33(4), 399-425

Delafield-Butt, J.T., and Trevarthen, C. (2013). Theories of the development of human communication. In: P. Cobley and P. Schultz (eds.), Theories and Models of Communication. Berlin/Boston: De Gruyter Mouton, pp.199-222.

Delafield-Butt, J.T., and Trevarthen, C. (2015). The ontogenesis of narrative: From movements to meaning. Frontiers of Psychology, 6:1157 doi: 10.3389/fpsyg.2015.01157

Delafield-Butt, J.T., and Trevarthen, C. (2017). On the brainstem origin of autism: Disruption to movements of the primary self. In: E. Torres and C. Whyatt (eds.), Autism: The Movement Sensing Perspective. Boca Raton, FL: Taylor and Francis CRC Press, pp.1-41.

Delafield-Butt, J.T., Pepping, G.-J., McCaig, C.D., and Lee, D.N. (2012). Prospective guidance in a free-swimming cell. Biological Cybernetics, 106, 283-293. doi:10.1007/s00422-012-0495-5

Donaldson, M. (1992). Human Minds: An Exploration. London: Allen Lane/Penguin Books.

Erickson, F. (2010). Musicality in talk and listening: A key element in classroom discourse as an environment for learning. In: Malloch, S. and Trevarthen, C. (eds.) Communicative Musicality: Exploring the Basis of Human Companionship. Oxford: Oxford University Press, pp.449-464.

Featherstone, S., Beswick, C., and Louis, S. (2008). Again! Again!: Understanding schemas in young children. London: Featherstone Education.

Fournier, K.A., Hass, C.J., Naik, S.K., Lodha, N., and Cauraugh, J.H. (2010). Motor coordination in autism spectrum disorders: a synthesis and meta-analysis. Journal of Autism and Developmental Disorders, 40, 1227-1240. 
Frank, B., and Trevarthen, C. (2012). Intuitive meaning: Supporting impulses for interpersonal life in the sociosphere of human knowledge, practice, and language. In: A. Foolen, U. Lüdtke, T. P. Racine, and J. Zlatev (eds.), Moving Ourselves, Moving Others: Motion and Emotion in Intersubjectivity, Consciousness, and Language. Amsterdam/Philadelphia: John Benjamins, pp.261-303.

Friedman, M.S. (2002). Martin Buber: The Life of Dialogue, 4th Edition. London and New York: Routledge

Gallagher, S. (2014). The cruel and unusual phenomenology of solitary confinement. Frontiers in Psychology, 5, 585. http://dx.doi.org/10.3389/fpsyg.2014.00585

Goodrich, B.G. (2010). We Do, Therefore We Think: Time, Motility, and Consciousness. Reviews in the Neurosciences, 21, 331-361

Gunn, K. C. M., and Delafield-Butt, J.T. (2016). Teaching children with autism spectrum disorder with restricted interests: A review of evidence for best practice. Review of Educational Research, 86(2), 408-430. doi:10.3102/0034654315604027

Hubley, P. and Trevarthen C. (1979). Sharing a task in infancy. In: I. Uzgiris (ed.) Social Interaction During Infancy, New Directions for Child Development, 4, 57-80. San Francisco: Jossey-Bass. doi: 10.1002/cd.23219790406

Jeannerod, M. (1988). The neural and behavioural organization of goal-directed movements. Oxford: Oxford University Press.

Kanner, L. (1943). Autistic disturbances of affective contact. Nervous Child, 2, 217-250.

Kennedy, J.F. (1962). Video. President John F. Kennedy’s address at Rice University, Houston, Texas, 12 September 1962. National Archives and Records Administration. Office of Presidential Libraries. John F. Kennedy Library. https://www.jfklibrary.org/Asset-Viewer/Archives/USG-15-29-2.aspx

Lashley, K.S. (1951). The problem of serial order in behavior. In: L.A. Jeffress (ed.), Cerebral Mechanisms in Behavior. New York: Wiley, pp.112-136.

Malloch, S., and Trevarthen, C. (2010). Musicality: Communicating the vitality and interests of life. In: S. Malloch and C. Trevarthen (eds.), Communicative Musicality: Exploring the Basis of Human Companionship. Oxford: Oxford University Press, pp.1-11.

Maturana-Romesin, H. and Verden-Zoller, G. (2008). The Origin of Humanness in the Biology of Love. Edited by Pille Bunnell. Exeter, UK/Charlottesville, VA: Imprint Academic 
Merker, B. (2007). Consciousness without a cerebral cortex: A challenge for neuroscience and medicine. Behavioral and Brain Sciences, 30, 63-134.

Merker, B. (2010). Ritual foundations of human uniqueness. In: Malloch, S. and Trevarthen, C. (eds.) Communicative Musicality: Exploring the Basis of Human Companionship. Oxford: Oxford University Press, p.45-60.

Nadel, J. (2014). How Imitation Boosts Development in Infancy and Autism Spectrum Disorder. Oxford: Oxford University Press.

Negayama, K., Delafield-Butt, J.T., Momose, K., Ishijima, K., Kawahara, N., Lux, E., . . . Konstantinos, K. (2015). Embodied intersubjective engagement in mother-infant tactile communication: A cross-cultural study of Japanese and Scottish mother-infant behaviours during infant pick-up. Frontiers in Psychology, 6. doi:10.3389/fpsyg.2015.00066

Northoff, G. and Panksepp, J. (2008). The trans-species concept of self and the subcortical-cortical midline system. Trends in Cognitive Sciences, 12(7), 259-264.

Osborne, N. (2010). Towards a chronobiology of musical rhythm. In: Malloch, S. and Trevarthen, C. (eds.) Communicative Musicality: Exploring the Basis of Human Companionship. Oxford: Oxford University Press, pp. 545-564.

Packard, A., and Delafield-Butt, J. T. (2014). Feelings as agents of selection. Biological Journal of the Linnean Society, 112, 332-353. doi:10.1111/bij.12225

Panksepp, J. (1998). The periconscious substrates of consciousness: Affective states and the evolutionary origins of the self. Journal of Consciousness Studies, 5, 566-582.

Panksepp, J. and Biven, L. (2012). Archaeology of Mind: Neuroevolutionary Origins of Human Emotions. New York: Norton

Penfield, W., and Jasper, H. H. (1954). Epilepsy and the functional anatomy of the human brain. London: Little, Brown, and Co.

Pezzulo, G., and Castelfranchi, C. (2009). Thinking as the control of imagination: A conceptual framework for goal-directed systems. Psychological Research, 73, 559-577.

Porges, S.W. (2011). The Polyvagal Theory: Neurophysiological Foundations of Emotions, Attachment, Communication, and Self-Regulation. New York/London: W.W. Norton. 
Porges, S.W., and Daniel, S. (2017). Play and dynamics of treating pediatric medical trauma. Insights from polyvagal theory. In Daniel, S. and Trevarthen, C.(Eds.) Rhythms of Relating in Children's Therapies: Connecting Creatively with Vulnerable Children. London: Jessica Kingsley, pp.113-125.

Porges, S.W., and Furman, S. A. (2011). The early development of the autonomic nervous system provides a neural platform for social behaviour: A polyvagal perspective. Infant and Child Development, 20, 106-118.

Reid, T. (1764). An Inquiry into the Human Mind on the Principles of Common Sense. London: A. Millar, and Edinburgh: A. Kincaid and J. Bell.

(Republished 1997, Edinburgh University Press.)

Reissland, N. and Kisilevsky, B. (eds.) (2015). Fetal Development: Research on Brain and Behavior, Environmental Influences, and Emerging Technologies. London: Springer Verlag

Rinehart N., and McGinley J. (2010). Is motor dysfunction core to autism spectrum disorder? Developmental Medicine and Child Neurology, 52, 8, 19197. doi: $10.1111 / \mathrm{j} .1469-8749.2010 .03631 . x$

Rinehart, N.J., Bellgrove, M.A., Tonge, B.J., Brereton, A.V., Howells-Rankin, D., and Bradshaw, J.L. (2006). An examination of movement kinematics in young people with high-functioning autism and Asperger's disorder: Further evidence for a motor planning deficit. Journal of Autism and Developmental Disorders, 36, 757-767.

Rizzolatti, G. and Gallese, V. (2003). Mirror neurons. In: Nadel L, (ed.) Encyclopedia of Cognitive Science. London: Nature Publishing Group, pp.37-42

Sander, L.W. (2008). Living Systems, Evolving Consciousness, and the Emerging Person: A Selection of Papers from the Life Work of Louis Sander. Edited by G. Amadei and I. Bianchi. Abingdon: Taylor and Francis.

Shewmon, D. A., Holmse, D. A., and Byrne, P. A. (1999). Consciousness in congenitally decorticate children: Developmental vegetative state as self-fulfilling prophecy. Developmental Medicine and Child Neurology, 41, 364-374.

Sinigaglia, C., and Rizzolatti, G. (2011). Through the looking glass: Self and others. Consciousness and Cognition, 20, 64-74.

Sperry, R.W. (1952). Neurology and the mind-brain problem. American Scientist, 40, 291-312. 
Stern, D.N. (2010). Forms of Vitality: Exploring Dynamic Experience in Psychology, the Arts, Psychotherapy and Development. Oxford: Oxford University Press.

Teitelbaum, P., Teitelbaum, O., Nye, J., Fryman, J., and Maurer R.G. (1998). Movement analysis in infancy may be useful for early diagnosis in Autism. Proceedings of the National Academy of Science. USA, 95, 13982-13987.

Trevarthen, C. (1995). Mother and baby - seeing artfully eye to eye. In: R. Gregory, J. Harris, D. Rose and P. Heard (eds.) The Artful Eye. Oxford: Oxford University Press, pp.157-200 and 8 colour plates.

Trevarthen, C. and Delafield-Butt, J.T. (2013a). Biology of shared experience and language development: Regulations for the inter-subjective life of narratives. In: Maria Legerstee, David Haley, and Marc Bornstein (eds.) The Infant Mind: Origins of the Social Brain. New York: Guildford Press, pp.167-199.

Trevarthen, C. and Delafield-Butt, J.T. (2013b). Autism as a developmental disorder in intentional movement and affective engagement. Frontiers in Integrative Neuroscience, 7, 49, 1-16. doi: 10.3389/fnint.2013.00049

Trevarthen, C., and Delafield-Butt, J.T. (2017). Development of consciousness. In: B. Hopkins, E. Geangu, and S. Linkenauger (eds.), Cambridge Encyclopedia of Child Developmnet. Cambridge: Cambridge University Press, pp.825-839.

Trevarthen, C., Aitken, K. J., Papoudi, C. and Robarts, J. Z. (1998). Children with Autism: Diagnosis and Interventions to Meet their Needs. (Second Edition). London: Jessica Kingsley ISBN 1853025550

Winn, P. (2012). Putting the brain into brainstem. Physiology News, 88, 29-32.

Wood, J. W. (1964). Behavior of chronic decerebrate rats. Journal of Neurophysiology, 27, 635644.

Zeedyk, M.S. (2008). (ed.) Promoting Social Interaction For Individuals With Communication Impairments. London and Philadelphia: Jessica Kingsley. 